\title{
TINGKAT PENGETAHUAN IBU TENTANG KEJANG DEMAM PADA ANAK USIA 6 BULAN SAMPAI 5 TAHUN DI PUSKESMAS KAMPAR TIMUR 2018
}

\author{
Roni Saputra ${ }^{1}$, Putri Wulandini $S^{2}$ Dayana Frilianova ${ }^{3}$ \\ ${ }^{1,2,3}$ Program Studi DIII Keperawatan Universitas Abdurrab \\ Email. Roni.Saputra@univrab.ac.id
}

\begin{abstract}
Febrile seizures is a disease that is quite common in infants. Half of the occurrence of febrile seizures occur recurrent febrile seizures, this occurs because the child's brain development is still not optimal enough in doing self-defense against the fever, resulting in the rise of febrile seizures. Parents often panic facing the event of febrile seizures. handling fever in children is very dependent on the parents. Level of knowledge of each different mother will lead to the management of fever in different children. This study aims to determine the level of knowledge of the mother about febrile seizures in children aged 6 mounth to 5 years in Puskesmas Kampar East Kampar District in 2018. this research use accidental sampling sampling technique and data collection is done by questioner. The research was conducted on 30 May - 9 June 2018 at Puskesmas Kampar East Kampar District. Sample was 50 respondents with univariate data analysis. The results of this study indicate that the mother's knowledge level is less with the number of 36 people (72\%). It is hoped for the Puskesmas to be able to make extantion program about things related to febrile definition dan febrile seizures. And for the mother around Puskesmas Kampar East Kampar District is expected to be more open to new information and more accepting suggestion from nurse and medical officer that exist, especially about information that is important and useful for family health.
\end{abstract}

Key Word : Level knowledge of mother, Febrile seizures

\section{ABSTRAK}

Kejang demam merupakan penyakit yang cukup sering dijumpai pada balita. Setengah dari kejadian kejang demam terjadi kejang demam berulang, hal ini terjadi karena perkembangan otak anak masih belum cukup optimal dalam melakukan pertahanan diri terhadap adanya demam, sehingga terjadi bangkitan kejang demam. Orang tua seringkali panik menghadapi peristiwa kejang demam. Penanganan demam pada anak sangat tergantung pada peran orang tua. Tingkat pengetahuan setiap ibu yang berbeda akan mengakibatkan pengelolaan demam pada anak yang berbeda pula. Penelitian ini bertujuan untuk mengetahui tingkat pengetahuan ibu tentang kejang demam pada anak usia 6 bulan sampai 5 tahun di Puskesmas Kampar Timur Kabupaten Kampar tahun 2018. Penelitian ini menggunakan teknik pengambilan sampel secara accidental sampling dan pengambilan data dilakukan dengan kuesioner. Penelitian dilakukan pada $30 \mathrm{Mei}-9 \mathrm{Juni}$ 2018 di Puskesmas Kampar Timur Kabupaten Kampar. Sampel berjumlah 50 responden dengan analisa data secara univariat. Hasil dari penelitian ini menunjukkan bahwa tingkat pengetahuan sebagian ibu adalah kurang dengan jumlah 36 orang (72\%). Diharapkan bagi pihak Puskesmas agar dapat membuat program penyuluhan terhadap hal-hal yang berkaitan dengan definisi demam dan kejang demam. Dan untuk ibu diharapkan agar lebih membuka diri terhadap informasi baru dan lebih menerima saran dari perawat maupun petugas medis yang ada, terutama mengenai informasi yang penting dan berguna untuk kesehatan keluarga.

Kata kunci : Tingkat pengetahuan ibu, kejang demam 


\section{PENDAHULUAN}

Kejang pada anak terutama pada balita sering kali tidak dimengerti oleh para orang tua. Akibatnya, orang tua kerap menjadi panik dan berpotensi melakukan langkah yang justru salah dan membahayakan untuk lebih memahami kejang pada anak, kita harus lebih mengetahui apa sesungguhnya yang menjadi penyebabnya. Otak manusia terdiri atas jutaan sel saraf, dimana sel-sel tersebut berkomunikasi satu sama lain melalui hantaran arus listrik. Ketika terdapat kejadian abnormal berupa pelepasan muatan listrik yang berlebihan diotak maka terjadilah kejang. (Tejani NR, Bachur, RG. 2010 dalam Afida 2012)

Serangan kejang demam pada anak yang satu dengan yang lain tidaklah sama, tergantung nilai ambang kejang masing-masing. Oleh karena itu setiap serangan kejang harus mendapat penanganan yang cepat dan tepat, apalagi kejang yang berlangsung lama dan berulang. Sebab keterlambatan dan kesalahan prosedur bisa mengakibatkan gejala sisa pada anak, bahkan bisa menyebabkan kematian. (Fida\&Maya, 2012).

Pengetahuan ibu tentang kejang demam adalah suatu pemahaman yang dimiliki oleh seorang ibu tentang demam yang berkisar antara $38,9^{\circ} \mathrm{C}-40,0^{\circ} \mathrm{C}$ yang dapat menyebabkan terjadinya kejang (Notoatmojo, 2007 \& Sodikin, 2012).

Para peneliti telah membuat berbagai kesimpulan bahwa bangkitan kejang demam berhubungan dengan usia, tingkatan suhu serta kecepatan peningkatan suhu, termasuk faktor hereditas juga memilki peran terhadap bangkitan kejang demam pada anggota keluarga penderita memiliki peluang untuk mengalami kejang lebih banyak dibandingkan dengan anak normal. Kejang demam merupakan kelainan neurologis yang paling sering terjadi pada anak, 1 dari 25 anak akan mengalami satu kali kejang demam (Harjaningrum, 2012).

WHO memperkirakan terdapat lebih dari 21,65 juta penderita kejang demam dan lebih dari 216 ribu diantaranya meninggal. Selain itu di Kuwait dari 400 anak berusia 1 bulan - 13 tahun dengan riwayat kejang, yang mengalami kejang demam sekitar 77\% (WHO, 2013 dalam Untari 2015) Insiden terjadinya kejang demam diperkirakan mencapai $4-5 \%$ dari jumlah penduduk di Amerika Serikat, Amerika Selatan, dan Eropa Barat. Namun di Asia angka kejadian kejang demam lebih tinggi, seperti di Jepang dilaporkan antara 6-9\% kejadian kejang demam, 5-10\% di India, dan 14\% di Guam (Hernal, 2010). Selain itu di Kuwait dari 400 anak berusia 1 bulan-13 tahun dengan riwayat kejang, yang mengalami kejang demam sekitar 77\% (WHO, 2013).

Dari hasil studi pendahuluan yang dilakukan peneliti mendapatkan data angka kejadian kejang demam yang terdapat pada rekam medik sepanjang tahun 2014-2016 di Puskesmas Kampar Timur Kabupaten Kampar sebanyak 28 anak dari usia 1-5 tahun dan merupakan angka kejadian kejang demam tertinggi. Bahkan dalam kurun waktu kurang dari 5 tahun terdapat beberapa anak yang kembali 
dirawat dengan kasus yang sama. Hasil wawancara oleh beberapa ibu, mereka mengatakan datang dengan keadaan cemas dan panik terhadap kondisi anaknya. Ibu tidak tahu tentang apa yag terjadi pada anak mereka, mengapa awalnya bisa terjadi seperti itu dan apa penyebabnya juga tidak mampu memberikan pertolongan terhadap anak mereka.

Berdasarkan data yang ada di Kampar Timur Kabupaten Kampar, pada tahun 2014 di bulan Januari sampai Desember terdapat 7 kasus kejang demam dan di tahun 2015 selama 5 bulan terakhir terdapat 12 kasus kejang demam. Dari kejadian itu dapat dilihat adanya peningkatan kejang demam dalam 1 tahun terakhir. Dari situlah peneliti tertarik untuk meneliti tentang "Tingkat pengetahuan ibu tentang kejang demam pada anak usia 6 bulan - 5 tahun di Puskesmas Kampar Timur Kabupaten Kampar".

Penelitian ini memiliki tujuan yaitu : Untuk mengetahui bagaimana tingkat pengetahuan ibu tentang kejang demam pada anak usia 6 bulan sampai 5 tahun di Puskesmas Kampar Timur Kabupaten Kampar.

\section{METODE PENELITIAN}

Dalam penelitian ini peneliti mengunakan jenis penelitian yang akan dilakukan adalah penelitian kuantitatif, dengan rancangan penelitian deskriptif untuk menggambarkan masalah penelitian.
(Polit and Beck, 2003 dalam Swarjana, 2012)

Informasi dan data pada penelitian ini diperoleh melalui pemberian kuesioner pada ibu-ibu yang bekunjung ke Puskesmas Kampar Timur Kabupaten Kampar. Setelah data diperoleh, kemudian dilakukan analisis yang bertujuan untuk memperoleh informasi tentang Tingkat Pengetahuan Ibu tentang Kejang Demam Pada Anak Usia 6 Bulan Sampai 5 Tahun di Puskesmas Kampar Timur Kabupaten Kampar Timur Tahun 2018.

Populasi adalah wilayah generalisasi yang terdiri atas objek/subjek yang mempunyai kualitas dan karakteristik tertentu yang ditetapkan oleh peneliti untuk dipelajari dan kemudian ditarik kesimpulannya (Setiawati,2013). Populasi yang akan diambil dalam penelitian ini adalah seluruh ibu yang memiliki anak berusia 6 bulan - 5 tahun dan tidak menderita epilepsi di lingkungan sekitar Puskesmas Kampar Timur Kabupaten Kampar.

\section{HASIL PENELITIAN DAN PEMBAHASAN}

Penelitian ini dilakukan di Puskesmas Kampar Timur Kabupaten Kampar pada tanggal 30 Mei - 9 Juni 2018. Responden penelitian adalah ibu-ibu pengunjung Puskesmas Kampar Timur Kabupaten Kampar dengan jumlah 50 responden. 
Tabel 1

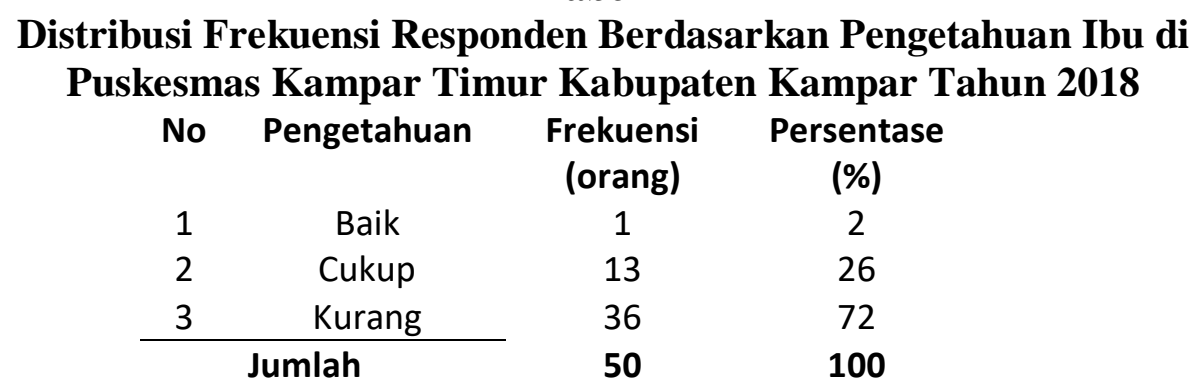

Berdasarkan Tabel 1 diatas diketahui bahwa tingkat pengetahuan ibu tentang kejang demam pada anak usia 6 bulan sampai 5 tahun di Puskesmas Kampar Timur Kabupaten Kampar mayoritas ibu yang berpengetatuan kurang yaitu sebanyak 36 orang (72\%), ibu yang berpengetahuan cukup yaitu sebanyak 13 orang (26\%), dan ibu yang berpengetahuan baik yaitu sebanyak 1 orang $(2 \%)$. Secara umum tingkat pengetahuan ibu tentang kejang demam pada anak adalah kurang.

\section{Pembahasan}

Penelitian ini dilakukan dengan tujuan untuk melihat serta mengetahui seberapa baik tingkat pengetahuan ibu tentang kejang demam pada anak usia 6 bulan sampai 5 tahun di Puskesmas Kampar Timur Kabupaten Kampar. Pada penelitian ini didapatkan hasil dari 50 responden (100\%), tingkat pengetahuan ibu tentang kejang demam yaitu 36 orang (72\%) berpengetahuan kurang, 13 orang (26\%) berpengetahuan cukup, dan 1 orang (2\%) berpengetahuan baik. Sehingga dari hasil tersebut dapat disimpulkan bahwa mayoritas responden berpengetahuan kurang tentang kejang demam. Data ini dipengaruhi oleh tingkat pendidikan

responden yang mana responden tertinggi ternyata mempunyai pendidikan terakhir SMA/Sederajat yaitu 27 orang $(54 \%)$. Sedangkan yang berpendidikan D1/Perguruan Tinggi hanya 2 orang (4\%). Tentu akan berbeda hasilnya apabila mayoritas responden berpendidikan terakhir D1 atau S1.

Menurut Afida UIN pada penelitiannya tahun 2012 menyebutkan bahwa pengetahuan responden yang baik mengenai pengetahuan ibu tentang kejang demam memiliki persentase cukup tinggi yaitu sebesar 65 orang (72.2\%), pengetahuan sedang sebanyak 22 orang (24.4\%), dan pengetahuan kurang sebanyak 3 orang $(3.3 \%)$. Hal ini tidak sesuai dengan penelitian ini.

Menurut Ervina pada penelitiannya tahun 2013 menyebutkan bahwa pengetahuan responden yang cukup mengenai pengetahuan ibu tentang kejang demam memiliki persentase cukup tinggi yaitu sebesar 25 orang (65.8\%), pengetahuan baik sebanyak 7 orang (18.4\%), dan pengetahuan kurang sebanyak 6 orang (15.8\%). Hal ini juga tidak sesuai dengan penelitian ini.

Menurut Susilowati pada penelitiannya tahun 2016 menyebutkan bahwa pengetahuan 
responden yang kurang tentang kejang demam memiliki persentase cukup tinggi yaitu sebesar 26 orang $(86,7 \%)$, pengetahuan cukup sebanyak 4 orang $(13,3 \%)$, dan pengetahuan baik sebanyak $0 \%$. Hal ini sesuai dengan penelitian ini.

Pengetahuan

menurut

Notoatmodjo (2007), merupakan hasil dari penginderaan manusia atau hasil tahu seseorang terhadap objek melalui indera yang dimilikinya (pendengaran, penglihatan, penciuman, perasa dan peraba). Salah satu faktor yang mempengaruhi pengetahuan adalah pendidikan. Pendidikan itu sendiri menentukan seseorang dalam menyerap dan memahami berbagai informasi yang diterima dari luar. Pada umumnya semakin tinggi pendidikan seseorang maka akan semakin baik pula pengetahuannya. Hal ini apabila dikaitkan dengan kejang demam, maka semakin tinggi tingkat pendidikan responden akan semakin baik pula pengetahuannya tentang kejang demam. Namun, karena mayoritas berpendidikan terakhir SMA/Sederajat sehingga pengetahuan ibu tentang kejang demam pada anak ada dalam kategori kurang.

Selain itu juga dipengaruhi oleh umur responden yang didominasi antara 29 - 38 tahun yaitu sebanyak 24 orang (48\%). Dimana umur tersebut termasuk umur yang paling banyak memiliki anak usia toddler. Umur juga berpengaruh terhadap pengetahuan seseorang dikarenakan semakin tua umur seseorang maka proses-proses perkembangan mentalnya bertambah baik dan matang untuk memperoleh dan menyerap berbagai informasi dari luar (Desmita, 2010). Biasanya, semakin banyak umur maka tingkat pengetahuan seseorang juga semakin banyak. Hal itu dikarenakan pengalaman hidup yang mereka tempuh lebih banyak daripada seseorang yang umurnya jauh lebih muda.(Wawan, A \& Dewi,2010). Namun perlu diketahui bahwa seseorang yang berumur lebih tua juga tidak mutlak memiliki pengetahuan yang lebih tinggi dibandingkan dengan seseorang yang lebih muda (Notoatmojo,2003). Beberapa diantaranya responden juga memiliki fasilitas yang cukup seperti televisi, radio, internet yang juga mendukung pengetahuan mereka tentang kejang demam.

Hasil dari sumber informasi tentang kejang demam yang dimiliki responden adalah sebanyak 31 orang (62\%) tidak pernah menerima sumber informasi tentang kejang demam, sebanyak 8 orang $(16 \%)$ menerima sumber informasi dari televisi/media massa, sebanyak 6 orang (12\%) menerima sumber informasi dari Tim kesehatan, sebanyak 5 orang $(10 \%)$ menerima sumber informasi dari buku/surat kabar. Kurangnya informasi yang diterima oleh responden menjadi penyebab kurangnya pengetahuan tentang kejang demam. Salah satu faktor yang mempengaruhi pengetahuan seseorang adalah informasi. Jika seseorang mendapatkan pengetahuan yang baik dari berbagai media seperti radio, televisi, internet, atau surat kabar maupun buku, maka hal tersebut dapat meningkatkan pengetahuan seseorang (Notoatmodjo, 2010). Sehingga apabila dihubungkan dengan kejang demam semakin 
banyak informasi yang didapat maka akan semakin baik pula pengetahuan responden tentang kejang demam. Begitu sebaliknya, apabila informasi yang diterima oleh responden kurang maka pengetahuan tentang kejang demam juga kurang

Dalam penelitian ini di dapatkan hasil sebanyak 21 orang (42\%) yang setuju jika mengompres dengan air hangat adalah tindakan yang paling tepat, 18 orang (36\%) setuju jika tindakan mengompres dengan air dingin adalah tindakan yang tepat dan 11 orang (22\%) setuju jika tindakan mengompres dengan air dingin atau dengan air hangat samasama benar. Hal ini menunjukkan bahwa dalam melakukan kompres demam tampaknya masih banyak yang belum dimahami tujuan dari kompres tersebutt, padahal kompres demam sering dilakukan karena masyarakat menerima kompres sebagai suatu pengelolaan demam yang sudah turun-temurun.

Seperti yang kita ketahui bahwa pentingnya pemilihan metode dalam melakukan kompres demam tampaknya masih kurang disadari oleh beberapa responden. Sebanyak 39 ibu dalam penelitian ini $(78 \%)$ mengaku memberi kompres demam untuk menurunkan suhu tubuh anaknya. Namun dalam pemberian kompres demam tampaknya masih perlu diperhatikan mengenai cara pemberian kompres demam yang tepat. Terdapat dua metode berbeda dalam pemberian kompres demam. Demam yang umum dapat diturunkan dengan pemberian kompres menggunakan air hangat dengan temperatur air $29,5^{\circ} \mathrm{C}-32^{\circ} \mathrm{C}$ supaya dapat memberikan sinyal ke hipotalamus dan memacu terjadinya vasodilatasi pembuluh darah perifer. Hal ini menyebabkan pembuangan panas melalui kulit meningkat sehingga terjadi penurunan suhu tubuh menjadi normal kembali. Pemberian kompres hangat dapat dilakukan apabila suhu tubuh anak diatas $38,5^{\circ} \mathrm{C}$ dan telah mengkonsumsi antipiretik setengah jam sebelumnya (NICE, 2013). Kompres dengan air dingin dapat dilakukan apabila kondisi suhu tubuh sangat tinggi (lebih dari $41^{\circ} \mathrm{C}$ ).

Pada penelitian yang dilakukan Damayati TT pada tahun 2008 di ruang rawat inap RSUD Dr. Moewardi Surakarta dengan sampel 34 orang, diambil kesimpulan bahwa sebagian besar pengetahuan ibu tentang demam dalam kategori sedang, perilaku kompres sebagian besar dalam kategori baik dimana sebanyak 46 responden $(43.4 \%)$ mengompres anaknya dengan air hangat. Hal ini tidak sesuai dengan penelitian ini. Menurut penelitian Tarigan dkk di Medan tahun 2006 menemukan bahwa 47 responden (47\%) mengaku diedukasi oleh dokter untuk kompres menggunakan air dingin dan hanya 22 responden (22\%) mengaku dianjurkan dokter untuk kompres menggunakan air hangat. Hal ini tidak sesuai dengan penelitian ini karena 11 orang $(22 \%)$ sudah banyak ibu yaitu 46 responden (43.4\%) yang mengompres anaknya dengan air hangat dan juga dengan air dingin.

Pertanyaan yang paling banyak dijawab salah adalah sebanyak 14 orang $(28 \%)$ tentang tanda dan gejala yang menandakan anak sedang mengalami kejang demam. Responden sebanyak 10 orang (20\%) yang masih tidak mengetahui tentang 
defenisi demam, sebanyak 34 orang (68\%) responden yang tidak mengetahui tentang defenisi kejang demam, sebanyak 46 orang (92\%) tidak mengetahui bahwa kejang demam dapat meningkatkan risiko penyakit epilepsi, hal ini dapat disebabkan karena responden yang menyalahartikan antara penyakit ayan atau epilepsi dengan kejang demam. Sebanyak 32 orang $(64 \%)$ tidak mengetahui bahwa kejang demam hanya terjadi pada bayi dan balita, sebanyak 32 orang $(64 \%)$ tidak mengetahui bahwa kejang demam umumnya tidak berbahaya dan tidak menimbulkan kematian, dan sebanyak 15 orang (30\%) tidak setuju bahwa anak yang mengalami kejang demam perlu diberikan obat lain selain obat penurun panas, sebanyak 39 orang (78\%) tidak membenarkan bahwa anak yang mengalami kejang demam akan memiliki gangguan pada mental dan pola pikir anak. Sebanyak 23 orang (46\%) bersikap tidak setuju pada pernyataan bahwa setiap demam akan meyebabkan kejang. Namun sebanyak 45 orang $(90 \%)$ paling banyak menjawab benar bahwa kejang demam dapat dan perlu dicegah dengan cara membawa anak ke Puskesmas/Klinik/Rumah Sakit terdekat.

Sesuai dengan penelitian Tarigan dkk bahwa 70 responden (70\%) mengaku bahwa hal yang paling ditakutkan responden bila anak demam adalah jika terjadi kejang. Oleh karena itu, orang tua memilih untuk langsung membawa anaknya ke Rumah Sakit atau Klinik Dokter terdekat. Umumnya mereka takut demam anaknya akan semakin tinggi apabila tidak segera ditangani meskipun demam yang terjadi masih bersifat demam ringan. Hal ini menunjukkan bahwa responden kurang mengerti saat yang tepat untuk menurunkan suhu tubuh anak yang mengalami demam. Persepsi yang salah ini patut diwaspadai karena dapat membawa kepada pengelolaan demam yang keliru. Beberapa studi melaporkan petugas kesehatan sering menganggap demam sebagai hal yang berbahaya dan ini membuat perawat sering merasa bingung menangani demam (Walsh, et al, 2005).

Sebagian besar responden 38 orang $(76 \%)$ berpendapat bahwa cara yang paling baik untuk menilai suhu anak adalah dengan meraba kening anak. Seperti pada penelitian yang dilakukan oleh Tarigan dkk, pada tahun 2006 dengan sampel 100 orang, didapatkan 38 responden merasakan demam melalui telapak tangan, 77 menjawab lokasi untuk merasakan demam adalah dahi. Hal ini sesuai dengan penelitian ini karena sebanyak 12 orang $(24 \%)$ yang mengukur suhu demam anak dengan thermometer.

Berdasarkan hasil penelitian ini, peneliti berpendapat pengetahuan ibu tentang kejang demam perlu ditingkatkan untuk mencegah terjadinya kejang demam pada anak. Peningkatan pengetahuan dapat dilakukan dengan pendidikan kesehatan yang meliputi definisi, etiologi, faktor risiko, pencegahan, penatalaksanaan, dan komplikasi tentang kejang demam.

\section{KESIMPULAN DAN}

SARAN

Tingkat pengetahuan ibu tentang kejang demam pada anak usia 6 
bulan 5 tahun di Puskesmas Kampar Timur Kecamatan . Bagi perawat dan tenaga medis agar melakukan penyuluhan dan penkes kepada masyarakat supaya masyarakat maupun para ibu lebih memahami lagi tentang demam, kejang demam dan bagaimana penanganan yang tepat untuk kejang demam ini.

\section{DAFTAR PUSTAKA}

Tejani NR, Bachur, RG. 2010. Padiatricc, Febrile Seizure. Cited at [18 Oktober 2017] at

http://emedicine.medspace. com/article/801500overview\#a0919

Hidayat AA (2008). Pengantar Ilmu Kesehatan Anak Untuk Pendidikan Kebidanan. Jakarta : Salemba Medika.

Kharis A. (2010). Defisiensi besi dengan parameter stfr sebagai factor resiko kebangkitan kejang demam. semarang : universitas diponegoro. diakses die print. undip. ac.id

Fida, Maya, (2012). Pengantar ilmu kesehatan anak. Jakarta: D.Medika

Notoatmojo, 2007 \& Sodikin, 2012. Prinsip perawatan demam pada anak. Yogyakarta: Pustaka Pelajar.

Khanis A. (2010). Defisiensi besi dengan parameter stfr sebagai faktor resiko bangkitan kejang demam. Semarang: Universitas Diponegoro. Diakses di eprints.undip.ac.id

WHO. (2005). A review of literature on healthy environment for the children in the eastern mediterranean region: status of children lead exposure. Diakses di http://www.emro.who.int/d $\underline{\text { saf/dsa 516.pdf }}$

Eny Susilowati, (2016).

Hubungan antara pengetahuan orang tua tentang penanganan demam dengan kejadian kejang demam berulang di ruang anak SDUD Dr. Soehadi Prijonegoro Sragen. Surakarta. Diakses di http://repository01-gdlenysusilo-1423-1-enysusi-)1.ac.id/710/pdf

Winda A, (2013). Hubungan Antara Pengetahuan

Dengan Perilaku Ibu

Tentang Pencegahan

Kejang Demam Pada

Balita Di Posyandu

Gondangsari Juwiring

Klaten. Stikes Kusuma

Husada Sarjana

Keperawatan, Surakarta.

Ervina, (2013). Tingkat

Pengethuan Ibu Tentang

Kejang Demam Dengan

Frekuensi Anak Toddler Di

Rawat Inap Puskesmas

Gatak Sukoharjo. FIK

Universitas

Muhammadiyah, Surakarta.

Wawan, A dan Dewi, M. 2010.

Teori dan Pengukuran

Pengetahuan, Sikap dan

Perilaku Manusia.

Yogyakarta : Nuha Medika.

Tarigan, T., Harahap, C.A., \& Lubis, S. (2007). Pengetahuan, sikap dan perilaku orangtua tentang 
demam dan pentingnya edukasi oleh dokter. Sari Pediatri. 8(3), 27-31.

Ikatan Dokter Anak Indonesia. (2013). Konsensus penatalaksanaan kejang demam. Jakarta: Badan Penerbit IDAI.

WHO, 2013 dalam Untari 2015. Hubungan antara Tingkat Pengetahuan Ibu tentang Kejang Demam dengan Frekuensi Kejang Anak Toddler Di Rawat Inap Puskesmas Gatak Sukoharjo. Fakultas Ilmu Kesehatan Universitas Muhammadiyah, Surakarta Notoatmojo, $2007 \quad \&$ Sodikin,2012. Prinsip perawatan demam pada anak. Yogyakarta: Pustaka Pelajar.

Arikunto (2010) Prosedur Penelitian Suatu Pendekatan Praktek. Edisi Revisi 2010. Jakarta : PT Rineka Cipta, 2010.

Lumbantobing. (2007). Kejang demam (febrile convulsions). FKUI: Jakarta

Doengoes, Marylinn E. (1999) Rencana asuhan keperawatan. Edisi 3. Jakarta: EGC.

IDAI, 2013. Recent Research on Febrile Seizures: A Review. Journal Neurol Neurophysical 4 (4): 1-6 Edisi Pertama. Jakarta : IDAI

Unit Kerja Koordinasi Neurologi IDAI 2006 dalam jurnal Triuntari 2013. Klasifikasi Kejang Demam.
Judha \& Rahil, 2011. Kegawatdaruratan kejang demam pada anak. Berita Ilmu Keperawatan. 1 (1): 97-100.

Nursalam. Konsep dan Penerapan Metodelogi Penelitian ilmu keperawatan Pedoman Skripsi, Tesis, dan instrumen penelitian keperawatan. Jakarta: Salemba Medika, 2008.

Swarjana, I Ketut. 2012. Metodelogi Penelitian Kesehatan.ed 1.Yogyakarta:AND.

RCN, 2013. Demam Pada Anak. Majalah Kedokteran Indonesia 2008:58:h.9

Notoadmojo. 2010. Metodelogi Penelitian Kesehatan. Jakarta : Rineka Cipta.

Potter \& Perry (2005). Buku Ajar Fundamental Keperawatan : Konsep, Proses, dan Praktik.Edisi 4.Volume 1. Jakarta : EGC.

Danim, Sudarwan. Riset Keperawatan:sejarah \& metodelogi. Jakarta: EGC, 2003.

Umar Husein. Riset Sumber Daya Manusia. Jakarta : PT Gramedia Pustaka Utama, 2005.

Walsh, et al, 2005. Recent research on febrile seizures: a review. J Neurol Neurophysiol. 4(165). Diakses di http://www.ncbi.nlm.nih.go $\mathrm{v} / \mathrm{pmcl}$ articles/PMC4220240/

Natoatmodjo, Soekidjo. Pendidikan dan Perilaku 
Kesehatan. Jakarta : Rineka Cipta. 2003.

Natoatmodjo, Soekidjo. Pendidikan dan Perilaku Kesehatan. Jakarta : Rineka Cipta, 2007.

Price, 2012. Buku Ajar Kesehatan Anak. Jakarta : Fakultas Kedokteran Universitas Indonesia

Setiadi. Konsep dan Penulisan Riset Keperawatan.Ed 1.Yogyakarta : Graha Ilmu. 2007.

Sugiono. Metode penelitian pendidikan. Bandung : Alfabeta, 2010.

Afida, 2012. Pengetahuan, Sikap Dan Perilaku Ibu Mengenai Kejang Demam Pada Anak Di Puskesmas Timur 2012. Jakarta : FKIK UIN Syarif Hidayatulah

Amalia K, Fatimah, Bennu HM. (2013). Faktor risiko kejadian kejang demam pada anak balita diruang perawatan anak rumah sakit umum daerah daya kota makassar. ISSN : 2302-1721. 1 (6): 1-9.

Doengoes, Marylinn E. (1999) Rencana asuhan keperawatan. Edisi 3. Jakarta: EGC.

Farsar AR, Kolahi AA, (2008). Can educational programs help ease parental anxiety following their child first febrile convulsion?. Department of Community Medicine, Faculty of Medicine. Iran $J$ Child Neurology. 2(3): 25-31. Diakses di http://journals.sbmu.ac.ir/in dex.php/ijen/article/view/28 $1 / 395$

Fuadi, Bahtera T, Wijayahadi N. (2010). Faktor resiko bangkitan kejang demam pada anak. Sari Pediatri .12 (3): 142-149.

Gunawan W, Kari K, Soetjiningsih. (2008). Knowledge, attitude, and practices of parents with children of first time and reccurent febrile seizure. Pediatrica Indonesiana. 48: 193-198. Diakses di http://paediatricaindonesian a.org/pdffile/48-4-1.pdf

Gunawan PI, Suharso D, (2012). Faktor risiko kejang demam berulang pada anak 42(2): $\quad$ 75-79. Media Medika Indonesia.

Hay WW, 2007. Current Pediatric diagnosis and treathment LARGE. The McGrew-Hill companies; 2007:17:h:642-7

Helmi, M. (2014). Perbedaan Manifestasi Klinis Kejang Demam pada Anak Anemia dengan Anak Tanpa anemia. Program pendidikan Sarjana Kedokteran Fakultas Kedokteran Universitas Diponegoro. Semarang.

Hidayat, Alimun. Metode Penelitian Keperawatan dan Teknik Analisis Data .Ed 1.Jakarta: Salemba Medika, 2007.

Hull D, Johnston D, (2008). Dasar-dasar pediatri Edisi 3. Jakarta: EGC.

Lee GM, Freidman JF, RossDegnan D, Hibberd PL, 
Goldmann DA. (2003). Misconception about colds and predictors of health service utilization. Pediatrics. 111: 231-236.. Diakses di http:// pediatrics. aappublications. org/content/ $111 /$ 2/231.full.pdf

Lumbantobing. (2007). Kejang demam (febrile convulsions). FKUI: Jakarta.

Maryatongo, (2007). Asuhan keperawatan anak dengan kejang demam di ruang luqman. Semarang: RS Roemani Semarang. Diakses di http://digilib.unimus.ac.id

Purwanti, Sri O, Maliya A, (2008). Kegawatdaruratan kejang demam pada anak. Berita Ilmu Keperawatan. 1 (1): 97-100.

Pusponegoro,2006. Dalam Afida, 2012. Pengetahuan, Sikap Dan Perilaku Ibu Mengenai Kejang Demam Pada Anak Di Puskesmas Timur 2012. Jakarta : FKIK UIN Syarif Hidayatulah

Putra, Rama H, Mulyadi, Ismanto AY, (2013). Hubungan pengetahuan perawat tentang kejang demam dengan penanganan kejang demam pada anak di instalasi rawat darurat anak (irda) dan ruang perawatan intensif (rpi) irina E Rsup Prof. Dr. RD. Kandou Manado. Diakses di

Rizkana NN, Trisnasari A, Sundari, (2012). Gambaran tingkat pengetahuan ibu tentang kejang deman pada balita di desa sukodadi kecamatan kangkung kabupaten kendal. Diakses di perpusnwu.web.id.

Seinfeld DO, Pellock JM, (2013). Recent research on febrile seizures: a review. J Neurol Neurophysiol. 4(165). Diakses di http://www.ncbi.nlm.nih.go $\mathrm{v} / \mathrm{pmcl}$ articles/PMC4220240/

WHO. (2005). A review of literature on healthy environment for the children in the eastern mediterranean region: status of children lead exposure. Diakses di http://www.emro.who.int/d saf/dsa 516.pdf. 